\title{
CORRELATION BETWEEN CESAREAN SECTION AND PERINATAL MORTALITY RATE
}

(C) by Acta Medica Saliniana ISSN 0350-364X

Type of manuscript: Professional papers

\section{Title:}

CORRELATION BETWEEN

CESAREAN SECTION

AND PERINATAL MORTALITY RATE

Authors:

Jasenko Fatušić ch, $^{1,}$ Maida Skokić ${ }^{1}$, Zlatan Fatušić ${ }^{2}$

DOI: $10.5457 / 499$

\section{Afiliations:}

${ }^{1}$ School of Medicine, University of Tuzla, Bosnia and Herzegovina, ${ }^{2}$ University Department of Gynecology and Obstetrics, University Clinical Center, Tuzla, Bosnia and Herzegovina

Received:

25.03.2019.

\section{Corresponding author:}

Zlatan Fatušić MD, PhD. Address:

Prof. dr. Ibre Pasic street bb, Tuzla,

Bosnia and Herzegovina.

email: zlatan.fatusic@ukctuzla.ba

Objectives: cesarean section rates show a wide variation among countries, ranging from $0,4-40 \%$, and continuous rise. Our aim was to test hypothesis that higher Cesarean rate than $15 \%$ does not correlates with lower perinatal mortality rate.

Methods: We analysed 18-year period with high-quality cesarean delivery and perinatal mortality rates information data. Data were analised by Chi-square test with Yate's correction for large values.

Results: Cesarean section rates has increasing trend. In first six-years of observed period (1998-2003) mean cesarean section rate was 17,24\%, in second (2004-2009) 19,33\% and in third (2010-2015) 23,97\%. In observed period mean perinatal mortality rate was 9,90\%o, with fluctuation of $20,70 \%$ to $3,82 \%$ o. In first six-years of observed period (1998-2003) mean perinatal mortality rate was $13,81 \%$, in second (2004-2009) $8,28 \%$ ond in third (2010-2015) 7,46\%o. These data clearly showed that increase of cesarean section rate more than $19,33 \%$ is not correlate with decreasing od perinatal mortality.

Conclusion: Despite many suggestions that improvement in perinatal mortality does not necessarily rely upon an ever-increasing cesarean section rate and recommendation by World Health Organisation that cesarean section rate should not exceed 10-15 percent to optimise neonatal outcomes, this recommendation may be too low, and suggests rate of $19 \%$.

Key words: cesarean section reate, perinatal mortality rate, correlation.

\section{INTRODUCTION}

Cesarean Section is the common major surgical procedure in obstetric practice (1). Cesarean section rates shows a wide variation among countries in the world, ranging from $0,4-40 \%$, and a continuous rise in the trend has been observed in past few decades (2). It is being because of development of effective antimicrobical agents, allied to advancement in surgical and anesthetic techniques, and rendered cesarean section a safe option to the obstetrician, preventing many maternal and fetal injuries. Until 1960's the increase in ceraean section rates had a direct impact on decreasing perinatal mortality in most developed countries (3). But, the decrease of perinatal mortality cannot be explained only by increased cesarean section rate. Many factors have the impact on perinatal mortality rate as advancements in prenatal care and education of pregnant women, use of corticosteroids in inducing of fetal pulmonary maturation, useness of ultrasonography, use of many effective tocolitic agents, improved obstetric care, and improved neonatal care.

However, the indiscriminate increase in cesarean sections, often performed without scientific basis, has become a multifactorial issue of difficult control (3). With the increasing importance of this procedure in our practice, it has become imperative to constantly evaluate not only the maternal but also the foetal outcome following cesarean operation.

The World Health Organisation (WHO) recommends that cesarean delivery rates should not exceed $10-15$ per 100 live births to optimize maternal and neonatal outcomes (4). Some studies suggest that there are differences in cesarean section rates between low-income, mediumincome and high-income countries. In low-income countries, a negative and statistically significant linear correlation was observed between cesarean section rates and perinatal and maternal mortality (2). Many autors published that improvement in perinatal mortality does not necessarily rely upon an evenincreasing cesarean section rate $(5,6,7,8$, $9,10,11)$, particularly in countries with low level of antenatal care (12). Contrary, some autors published that higher cesarean section rate is associated with improved neonatal outcomes and lower maternal or neonatal mortality in countries with up to 
$15-19 \%$ per 100 live births (4), particularly in lowincome countries (2).

The aim of thist study is determining the perinatal mortality rate among women delivered through cesarean section, find relationship between cesarean section rate and perinatal mortality rate, and test hypothesis that higher Cesarean rate inversly correlates to perinatal mortality rate.

\section{METHODS}

A retrospective study was carried out to determine the occurance of cesarean section deliveries, as well as early neonatal and perinatal mortality rates from januar 1998 to december 2015. Obstetric care was carried at University Hospital Tuzla, Bosnia and Herzegovina. We analysed 18-year period from 1998 to 2015 because this is period with high-quality cesarean delivery and perinatal mortality rates information data.

Early neonatal mortality was obtained by dividing the total number of deaths of newborns aged less than 7 days by the total number of live births during a given period. Perinatal mortality was calculated by dividing the total number of deaths of fetuses with more than 28 weeks of gestation (when the date of last menstrual period was unknown, a fetal weight greater than 1,000 $\mathrm{g}$ was calculated) plus number of deaths of newborns aged less than 7 days, by the total number of stillbirths and live births during a given period.

Data were analised by Chi-square test with Yate's correction for large values.

\section{RESULTS}

Between January 1998 and December 2015 , a total of of 77,258 deliveries were performed at Univerity hospital Tuzla. Out of 77,258 deliveries, 15,380 (19,90\%) were performed by cesarean section. Figure 1 . showes relative ratio between total number of deliveries and deliveries performed by cesarean section.

Total number of deliveries fluctuated between 3574 in 2015 to 5483 in 1998 with evident decreasing tendency. A cesarean section rates fluctuated between $15,53 \%$ in 1998 to $25,68 \%$ in 2014 with evident increasing tendency.

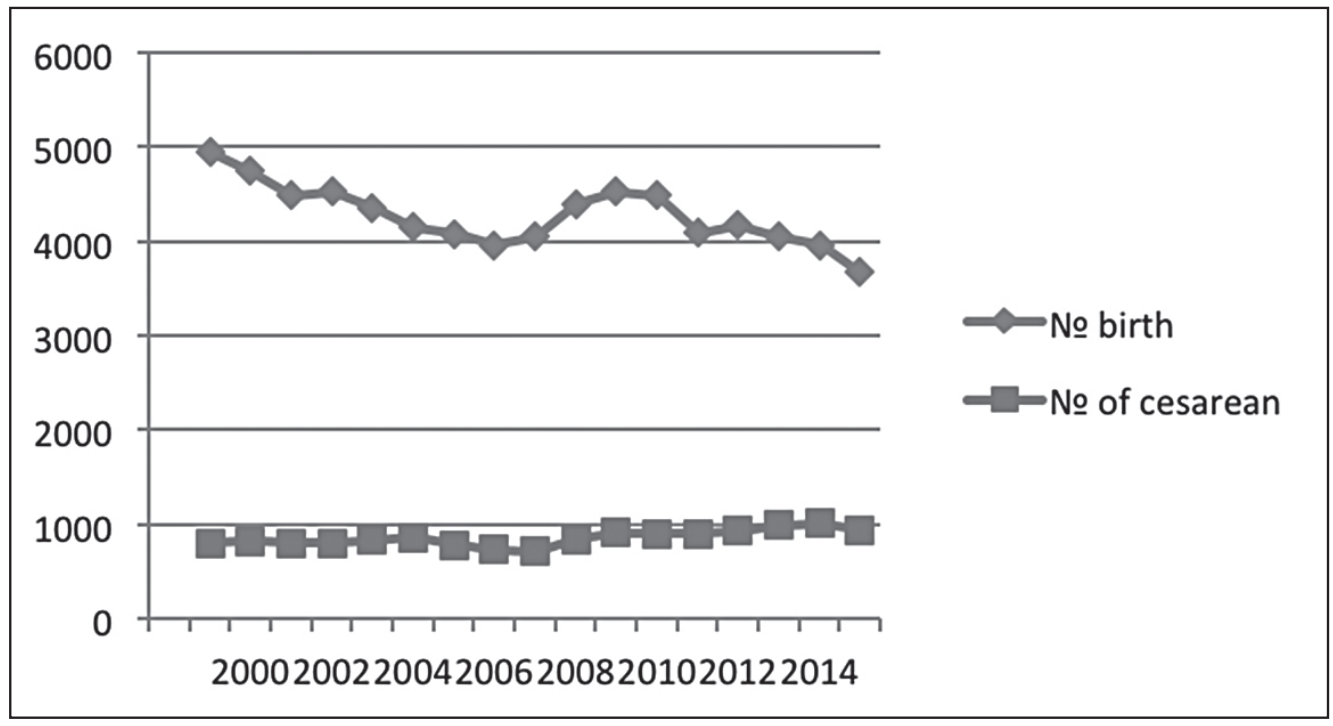

Figure 1. Relative ratio between total number of deliveries and deliveries performed by cesarean section

Figure 2. showes trend in cesarean section rates wich had evident increasing trend. In first six years of observed period (1998-2003) mean cesarean section rate was $17,24 \%$. In second period (2004-2009) it was $19,35 \%$ and in third period (1010-2015) was $23,97 \%$.

In observed period mean perinatal mortality (PNM) rate was $9,90 \%$, with fluctuation of $20,70 \%$ in 1998 to $3,82 \%$ in 2004 . In first six years of observed period (1998-2003) mean perinatal mortality rate was $13,81 \%$, in second six-year period (2004-2009) was $8,28 \%$ and in third period (2010-2015) was 7,46\%o. (Figure 3.).
Between first and second six-year observed period, we did not finde statistical difference in cesarean section rates $(17,24 \%$ vs $19,33 \%$ : $P<0,01)$, as well as between first and third period $(17,24 \%$ vs. $23,97 \%$ : $P<0,01)$ and second and third observed period (19,33\% vs. $23,97 \%$ : $\mathrm{P}<0,001$ ).

Between first and second six-year period, we did finde statistical difference in perinatal mortality rates $(13,81 \%$ vs. 8,28\% : $\mathrm{P}<0,001)$ but we did not found statistical difference in perinatal mortality rates between second and third observed period $(8,28 \%$ vs. 7,46\% : $\mathrm{P}=0,33: \mathrm{P}>0,05)$. 


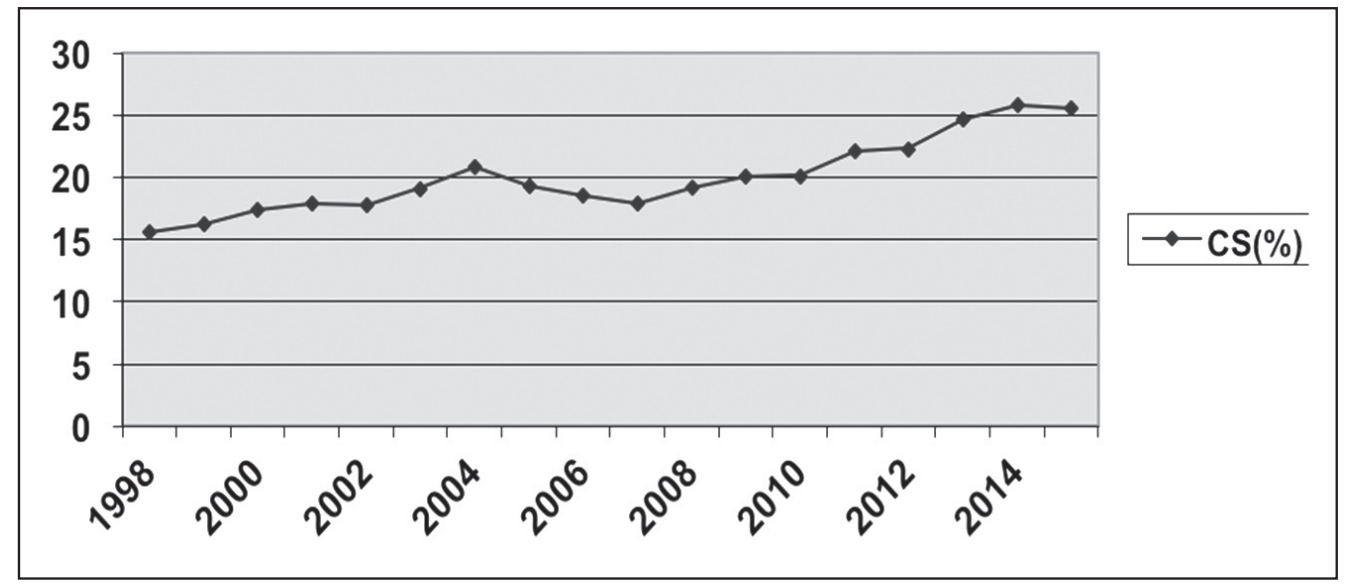

Figure 2. Cesarean section rates (\%) in period 1998-2015

These data clearly showed that increase of cesarean section rate up to $19,33 \%$ were associated with lower perinatal mortality rate, but cesraean sectio rate more than $19,33 \%$ is not correlate with decreasing od perinatal mortality rate.
Figure 3. combines cesarean sections and perinatal mortality rates and clearly shows increasing tendency of cesarean delivery rates at the same time with decreasing tendency of perinatal mortality rates.

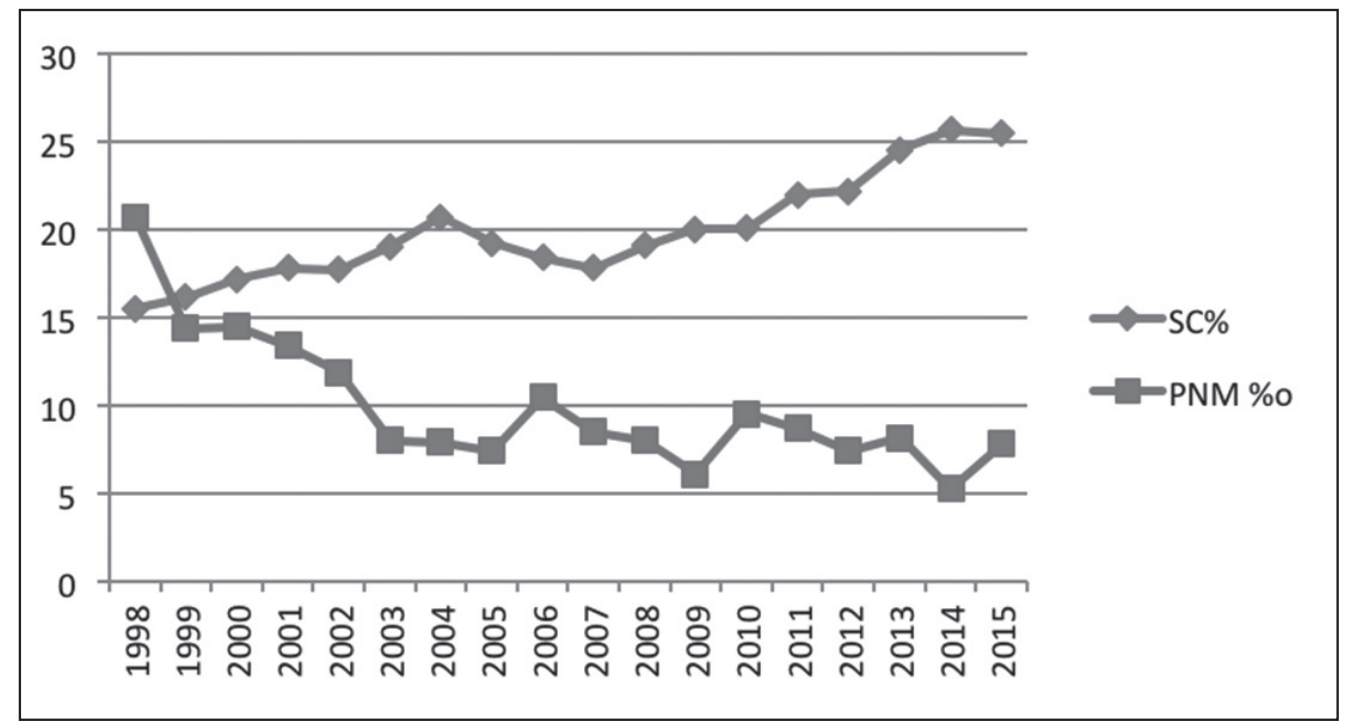

Figure 3. Cesarean section (\%) and perinatal mortality rates (\%o)

\section{DISCUSSION}

Our study findings confirmed same trends seen worldwide. Until the 1960's increasing cesaren section rate was found to have a direct impact on decrease of perinatal mortality (13). According to Nielsen et al. (14) cesarean section and perinatal mortality rates do not necessarily have an inverse correlation, a decrease in perinatal mortality cannot be explained solely by increased cesarean section rates, since many factors such as prenatal, obstetric, and neonatal care, socioeconomic conditions and better health organisation also play an important role. Meehan et al. (15) observed that an increase of cesarean section rates was only associated with a decreasing of perinatal mortality when cesarean section were indicated based on restricted obstetric criteria. Many studies present data wich confirm theory that increasing cesarean section rate is not inversily correlate with perinatal mortality rate $(5,6,7)$.

Meehan et al. (15) showed that increase of cesarean section rates was only associated with reduction of perinatal mortality when cesarean section were indicated based on restricted obstetric criteria not due to iteration. The autors recommendet a rigorous screening policy before performing a cesarean section so that perinatal molrtality could be effectively reduced.

According to 0' Driscoll and Foley (16), the increase in cesarean section rates has not contributed to reduced perinatal mortality after their study at the National Maternity Hospital in Dublin, and they reported 
cesarean section rates ranging from 4,2\%-4,8\% and simultaneously decreasing perinatal mortality rate in range of $42,1 \%$ o to $16,8 \%$ o wich strongly evidencing that cesarean section rates has not a direct impact on perinatal mortality.

Lumbiganon (9) showed in his study that women who give birth by cesarean section may be at an increased risk for negative consequences on maternal health, but with improved neonatal outcomes in cases of abnormal fetal presentation, and suggest that cesarean section be performed only when medically necessary.

Based on WHO systematic review, increasing section cesarean rates up to $10-15 \%$ at the population level are associated with decreases in maternal, neonatal and infant mortality (17).

The results of present studies showed permanently increasing tendency of cesarean section rate from $15,53 \%$ to $25,68 \%$, as in many countries $(17,18)$ and decreasing trend of perinatal mortality rates.

In our study, in analising period from year 1998-2015 we found permanent increasing cesarean section rate ranging from $15,3 \%$ to $25,67 \%$ with mean value of $19,90 \%$. At the same time perinatal mortality rate

\section{REFERENCES}

1. Porreco RP, Thorpe JA. The Cesarean Birth. Epidemic trends, Causes and Solutions. Am J Obstet Gynaecol. 1996;175:369-74.

2. Althabe F, Sosa C, Belizan JM, Gibbson L, Jacquerioz F, Bergel E. Cesarean section rates and maternal and neonatal mortality in low-, medium-, and high-income countries:an ecological study. Birth. 2006;33(4):270-7.

3. Silva Pereira JM. Incidencia inflacionaria do parto cesareo:mortalidadematerna e perinatal. J Bras Ginecol. 1986;96:39-44.

4. Molina G, Thomas GW, Lipsitz SR, Esquivel MM, et al. Relationship between Cesarean Delivery rate and maternal and Neonatal Mortality. JAMA. 2015;314(21):2263-70. doi: 10.1001/jama.2015.15553

5. Pearson JW. Cesarean section and perinatal mortality: A nineyear expirience in a city/county hospital. AmJ Obst Gyncol. $1984 ; 148(2): 155-9$

6. Wirakusumah FF. Maternal and perinatal Mortality/Morbidity Associated with Cesarean section in Indonesia. J Obstet Gynaecol. 1995;21(5):475-81.

7. Duarte G, Coltro PS, Bedone VB, Nogueira AA, Gelonezzi GM, Franco LJ. Trends in the modes of delivery and their impact on perinatal mortality rates. Rev Saude Publica. 2004;38(3):379-84.

8. Ziadeh SM, Sunna El. Decreased cesarean birth rates and improved perinatal outcome:a seven-year study. Birth. 1995;22(3):144-7.

9. Lumbiganon P. Method survey on maternal and perinatal health 2007-2008. Lancet. 2010;375(9713):490-9. doi: 10.1016/ S0140-6736(09)61870-5

10. Volpe FM. Correlation of Cesarean rates to maternal and infant mortality rates: an ecologic study of official international data. Rev Panam salud publica. 2011;29(5):303-8. showed permanent decreasing tendency in range from $20,70 \%$ o to $3,82 \%$.

Cesarean section rate up to $19,33 \%$ was followed by decreasing perinatal mortality rate in our observed period wich is similar to results of Molina et al. (4) and Volpe (10). But, cesarean section rate more than $19,33 \%$ in our study, was not followed by decrease of perinatal mortality rate. That is higher cesarean section rate than WHO recommended $(10-15 \%)$ to optimise maternal and neonatal outcomes.

In conclusion, many factors must have contributed to the reduced perinatal mortality, such as better prenatal and neonatal care. One of the main points of present sudy was to show that the reduction of perinatal mortality was not affected by permanent rising rates of cesarean sections. Despite many suggestions that improvement in perinatal mortality does not necessarily rely upon an ever-increasing cesarean section rate and recommendation by World Health Organisation that cesarean section rate should not exceed 10-15 per one hundred live births to optimise neonatal outcomes, this recommendation may be too low, and suggests rate of 19 percent of cesarean setion rate in improoving better perinatal outcomes.

11. Jonsdottir G, Smarason AK, Geirsson RT, Bjarnadottir RI. No correrelation between cesarean section rates and perinatal mortality of singleton infants over 2,500 g. Acta Obstet Gynecol Scand. 2009;88(5):621-3. doi: 10.1080/00016340902818196

12. Abiodun OM, Balogun OR. A review of cesarean sections associated with perinatal mortality at the University of Ilorin teaching hospital. Nigerian Journal of Clinical Practice. 2009;12(3):248-51.

13. Hudić I, Bujold E, Fatušić $Z$, Skokić F, Latifagić A, Kapidžić $M$, Fatušić J. The Misgav-Ladach method of cesarean section: a step forward in operative technique in obstetrics. Arch Gynecol Obstet. 2012;286(5):1141-6. doi: 10.1007/s00404-012-2448-6

14. Nielsen TF, Hokegard $\mathrm{KH}$, Ericson A. Cesarean section and perinatal mortality in Sweden in 1981. Acta Obstet Gynecol Scand. 1986;65:865-7.

15. Meehan FP, Burke G, Casey C, Sheil JG. Delivery following cesarean section and perinatal mortality. Am J Perinatol. 1989;6:90-4.

16. O'Driscol K, Foley M. Correlation of decrease in perinatal mortality and increase in cesarean section rates. Obstet Gynecol. 1983;61:1-5.

17. Betran AP, Torloni MR, Zhang J, Ye J, Mikolajczyk R, DenruxTharaux $C$ et al.. What is the optimal rate of caesarean section at the population level? A systematic review of ecologic studies. Reprod Health. 2015;12(1):57. doi: 10.1186/s12978-015-0043-6

18. Vogel JP, Betran AP, Vindevoghel N, Sousa JP, Torloni MR, Zhang J et al. On behalf of the WHO Multi-Country Survey on Maternal and Newborn Health Research Network. Use the Robson classification to asses caesarean section trends in 21 countries: a secondary analysis ot two WHO multicountry surveys. Lancet Global Health. 2015;3(5):260-270.irth 2014;41(3):237-43. doi: $10.1111 / 1471-0528.13266$ 